\title{
The development of a patient-specific method for physiotherapy goal setting: a user-centered design
}

Citation for published version (APA):

Stevens, A., Koke, A., van der Weijden, T., \& Beurskens, A. (2018). The development of a patient-specific method for physiotherapy goal setting: a user-centered design. Disability and Rehabilitation, 40(17), 20482055. https://doi.org/10.1080/09638288.2017.1325943

Document status and date:

Published: 01/01/2018

DOI:

10.1080/09638288.2017.1325943

Document Version:

Publisher's PDF, also known as Version of record

Document license:

Taverne

Please check the document version of this publication:

- A submitted manuscript is the version of the article upon submission and before peer-review. There can be important differences between the submitted version and the official published version of record.

People interested in the research are advised to contact the author for the final version of the publication, or visit the DOI to the publisher's website.

- The final author version and the galley proof are versions of the publication after peer review.

- The final published version features the final layout of the paper including the volume, issue and page numbers.

Link to publication

\footnotetext{
General rights rights.

- You may freely distribute the URL identifying the publication in the public portal. please follow below link for the End User Agreement:

www.umlib.nl/taverne-license

Take down policy

If you believe that this document breaches copyright please contact us at:

repository@maastrichtuniversity.nl

providing details and we will investigate your claim.
}

Copyright and moral rights for the publications made accessible in the public portal are retained by the authors and/or other copyright owners and it is a condition of accessing publications that users recognise and abide by the legal requirements associated with these

- Users may download and print one copy of any publication from the public portal for the purpose of private study or research.

- You may not further distribute the material or use it for any profit-making activity or commercial gain

If the publication is distributed under the terms of Article $25 \mathrm{fa}$ of the Dutch Copyright Act, indicated by the "Taverne" license above, 


\title{
The development of a patient-specific method for physiotherapy goal setting: a user-centered design
}

\author{
Anita Stevens, Albère Köke, Trudy van der Weijden \& Anna Beurskens
}

To cite this article: Anita Stevens, Albère Köke, Trudy van der Weijden \& Anna Beurskens (2018) The development of a patient-specific method for physiotherapy goal setting: a user-centered design, Disability and Rehabilitation, 40:17, 2048-2055, DOI: 10.1080/09638288.2017.1325943

To link to this article: https://doi.org/10.1080/09638288.2017.1325943

+ View supplementary material $[\pi$

Submit your article to this journal ¿

Q View related articles ¿

Citing articles: 10 View citing articles $\sqsubset$
Published online: 13 May 2017.

山ll Article views: 1612

View Crossmark data $\nearrow$ 


\title{
The development of a patient-specific method for physiotherapy goal setting: a user-centered design
}

\author{
Anita Stevens $^{\mathrm{a}, \mathrm{b}}$, Albère Köke ${ }^{\mathrm{a}, \mathrm{c}, \mathrm{d}}$, Trudy van der Weijden ${ }^{\mathrm{b}}$ and Anna Beurskens ${ }^{\mathrm{a}, \mathrm{b}}$ \\ ${ }^{\mathrm{a}}$ Faculty of Health, Zuyd University of Applied Sciences, Heerlen, The Netherlands; ${ }^{\mathrm{b}}$ Department of Family Medicine, Maastricht University, \\ CAPHRI School for Public Health and Primary Care, Maastricht, The Netherlands; 'Adelante Centre of Research in Rehabilitation, Hoensbroek, \\ The Netherlands; ${ }^{\mathrm{d}}$ Department of Rehabilitation Medicine, Maastricht University, Maastricht, The Netherlands
}

\begin{abstract}
Purpose: To deliver client-centered care, physiotherapists need to identify the patients' individual treatment goals. However, practical tools for involving patients in goal setting are lacking. The purpose of this study was to improve the frequently used Patient-Specific Complaints instrument in Dutch physiotherapy, and to develop it into a feasible method to improve physiotherapy goal setting.

Methods: An iterative user-centered design was conducted in co-creation with the physiotherapists and patients, in three phases. Their needs and preferences were identified by means of group meetings and questionnaires. The new method was tested in several field tests in physiotherapy practices.

Results: Four main objectives for improvement were formulated: clear instructions for the administration procedure, targeted use across the physiotherapy process, client-activating communication skills, and a client-centered attitude of the physiotherapist. A theoretical goal-setting framework and elements of shared decision making were integrated into the new-called, Patient-Specific Goal-setting method, together with a practical training course.

Conclusions: The user-centered approach resulted in a goal-setting method that is fully integrated in the physiotherapy process. The new goal-setting method contributes to a more structured approach to goal setting and enables patient participation and goal-oriented physiotherapy. Before large-scale implementation, its feasibility in physiotherapy practice needs to be investigated.
\end{abstract}

\section{ARTICLE HISTORY}

Received 7 November 2016

Revised 30 March 2017

Accepted 28 April 2017

\section{KEYWORDS}

Goal setting; patient participation; physiotherapy; user-centered design; clientcentered care; patientspecific instruments

\section{IMPLICATIONS FOR REHABILITATION}

- Involving patients and physiotherapists in the development and testing of a goal-setting method, increases the likelihood of its feasibility in practice.

- The integration of a goal-setting method into the physiotherapy process offers the opportunity to focus more fully on the patient's goals.

- Patients should be informed about the aim of every step of the goal-setting process in order to increase their awareness and involvement.

- Training physiotherapists to use a patient-specific method for goal setting is crucial for a correct application.

\section{Introduction}

To deliver client-centered care, physiotherapists need to identify patient's individual treatment goals [1-3]. Involving the patient in this goal-setting process has positive effects on treatment adherence, motivation, and satisfaction [4-10]. In routine practice, however, it appears that patients are hardly involved in goal setting and patients are not fully aware of the active role they could play in this process $[7,9,11-16]$. Physiotherapists find shared goal setting difficult, due to time constraints, limited skills and the fact that they are not used to involving patients in treatment [14,16-18]. Although professional profiles and clinical guidelines for physiotherapists emphasize the importance of goal setting [19-21], we are not aware of any practical guidelines for conducting the actual goal-setting process in routine practice.

Goal setting in everyday practice can be supported by structured methods, frameworks, and measurement instruments, which can enhance patient participation [5,13,22-26]. Patient-specific instruments are particularly suitable for this purpose, as they actively involve patients in the identification of personally relevant issues to work on in therapy $[22,27,28]$. Suitable instruments for this purpose include the Canadian Occupational Performance Measure (COPM) [29] in occupational therapy, and the PatientSpecific Complaints instrument (PSC) [30] or the Patient-Specific Functional Scale (PSFS) [31] in physiotherapy. The PSC is one of the most frequently used instruments in community-based physiotherapy practices in the Netherlands [32], and involves four steps. First, the patient's main problems are identified at the activities level of the International Classification of Functioning, Disabilities and Health Problems (ICF) [33]. In the second step, the activity problems thus identified are prioritized, and in the third step, the perceived "difficulty to perform the activity" is scored on a numeric rating scale (NRS) $(0=$ easy to perform, $10=$ impossible to perform). In the last step, the PSC can be used to evaluate the 
patient's progress during or after treatment. The psychometric qualities of the PSC and PSFS regarding reliability and validity are good, and their responsiveness is high [34-37].

Although physiotherapists regard the PSC as having the potential to contribute to goal setting and encourage patient participation, its actual use seems to be suboptimal $[11,16]$. Recent qualitative analyses of its use in everyday practice revealed that its potential for personalized goal setting is not fully utilized $[11,16]$. For example, the PSC was not uniformly administered, and the selected problem activities were not integrated into the further physiotherapy process. This meant that the PSC was used as a standalone instrument, mainly to meet external audit obligations [16]. Furthermore, patients were not invited to fully participate in the goal-setting process and to reflect on and express their own functioning or potential goals for therapy [11,16]. This often resulted in the physiotherapist taking the lead in formulating treatment goals and deciding on the treatment plan in a one-way process. As a consequence, goal setting was not always tailored to the patient's individual problems and physiotherapy treatment was not as client-centered as it could have been.

Based on these findings, and after discussions with experts in the field, we decided to improve the existing PSC instrument in co-creation with its users, i.e., the physiotherapists and the patients. User involvement in development processes is associated with significant benefits such as gaining insight into the users' perspectives, generating new ideas and improving usability [38]. Furthermore, good usability or feasibility is essential if an instrument is to be used in daily practice $[32,39]$. The purpose of this study was to improve the PSC instrument, and to develop it into a feasible method to improve physiotherapy goal setting in community-based physiotherapy practices.

\section{Methods}

The development strategy was based on a user-centered design described in the literature, consisting of several key principles [40]. First, the process should be "user-focused". This was ensured by basing the development process on the patients' and physiotherapists' experiences as assessed in a previous qualitative study $[11,16]$. Representative users, i.e., physiotherapists and patients, participated continuously in the entire development process to ensure "active user involvement". In addition, several experts were consulted at the beginning of and during the development process. Other key principles, such as "prototyping" and "evaluating use in context" were applied by developing, testing and evaluating the draft version in practice. User representatives had been selected in a previous study, which analyzed the actual use of the PSC instrument in the goal-setting process $[11,16]$. The results of this study were used as input for the present study.

Our development process was iterative and consisted of three phases: (1) identification of the objectives for improvement, (2) development of the draft version, and (3) evaluation of the feasibility in practice (Figure 1). Each phase delivered input for the next phase.

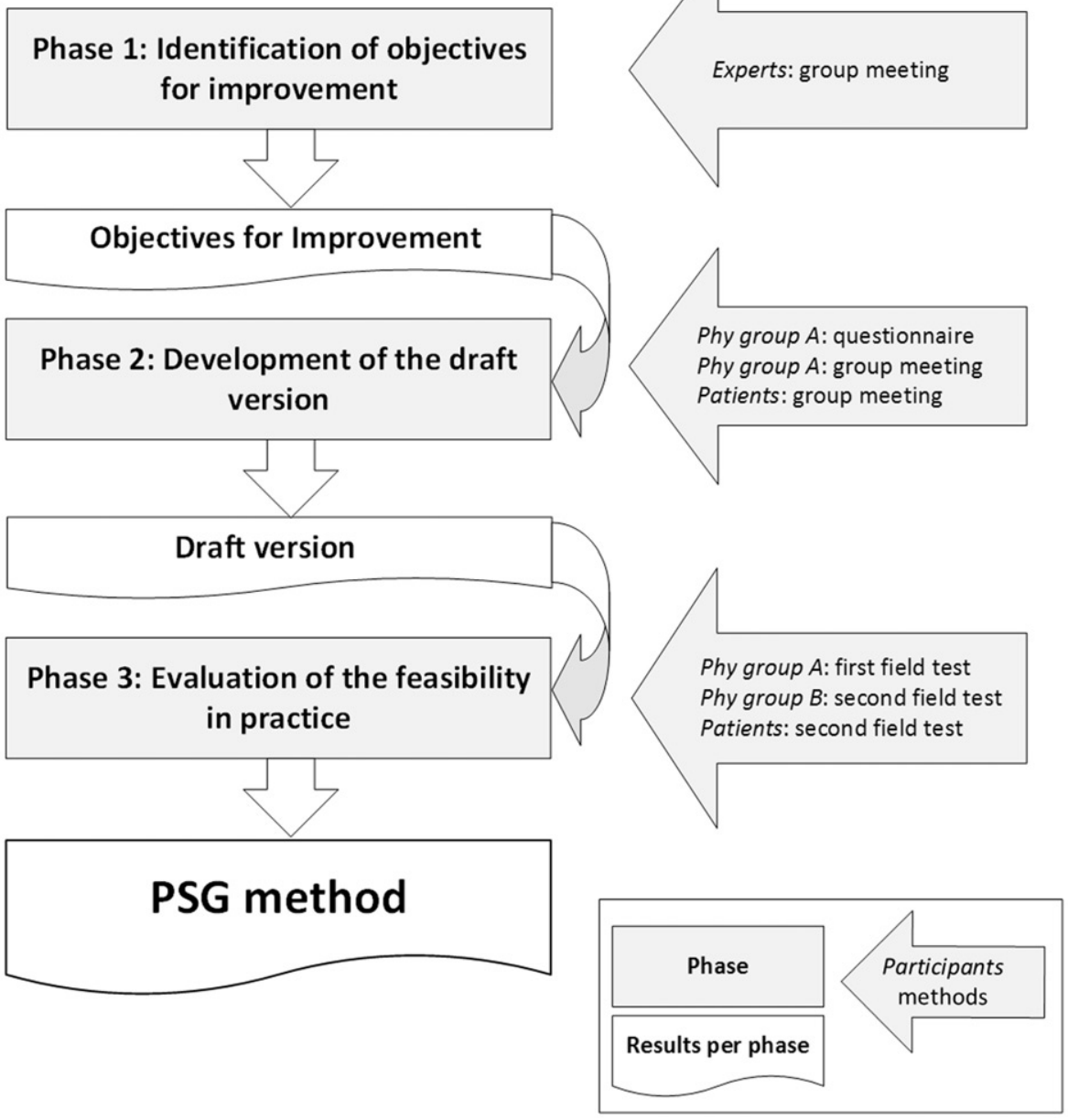

Figure 1. User-centered development process. 


\section{Phase 1: identification of the objectives for improvement}

In the first phase, seven experts on the use of the PSC instrument, on communication, on goal setting, and/or on shared decisionmaking, were invited for a two-hour meeting. Here, we presented the findings of our previous analysis $[11,16]$, explored additional experiences, and discussed ideas to improve the PSC, as well as its use in routine practice. The result of this meeting was a list of objectives for improvement of the PSC instrument, which was used as input for the next phase.

\section{Phase 2: development of the draft version}

One group of physiotherapists and one group of patients participated in this phase. Physiotherapists who were asked to participate belonged to a group of 10 physiotherapists who had participated in our previous qualitative study, where they were interviewed about the use of the PSC instrument $[11,16]$. Seven of them (group A) (five men, two women), aged 34-54 years (median: 45 years), from seven different community-based practices, were able to participate in the present study. The objectives for improvement defined in phase 1, were listed in a questionnaire and sent to them by email with the request to write down potential solutions to address these objectives. The physiotherapists were additionally asked to attend a subsequent group meeting with the aim of achieving consensus about the draft version and discussing strategies for further implementation.

Participants for the patient group were purposively sampled by a regional patient organization that advocates patient empowerment. Patients could be included if they had a chronic disorder, had undergone physiotherapy treatment in the past, and were able to think at a more abstract level, i.e., to act as patient representatives. We wanted four patients to attend the patient meeting, in order to introduce the patients' perspective into the further improvement of the PSC instrument.

During the group meetings, the nominal group method was used. This qualitative methodology is a structured procedure for generating information from target groups and ensures active participation of all participants, and a final consensus [41].

The physiotherapists' and patients' contributions were summarized and discussed by three of the authors (AS, AK, $A B$ ) and finally processed into a draft version of the new method.

\section{Phase 3: evaluation of the feasibility in practice}

The third phase involved testing and evaluating the feasibility of the draft version in two field tests in practice. In the first field test, four physiotherapists from group A (two men, two women), aged 34-54 years (median: 40.5 years) were asked to apply the draft version in, at least three patients with a chronic disorder. They were given verbal and written instructions for administering the new method, and used it in an iterative field test in two 6-week tracks. After the first track the first author evaluated the physiotherapists' experiences in individual interviews, while after the second track the therapists gave their feedback by email. All feedback was discussed in the project team and processed to develop a second draft version. This second version was tested and evaluated in a second field test by a larger user group (group B). Participants for group B were recruited from the internship supervisors of the School for Physiotherapy, Zuyd University of Applied Science, Heerlen, the Netherlands. The field test plan was presented at the annual internship meeting and the attending physiotherapists were invited to indicate if they were interested. The group was to consist of 12 physiotherapists, who could be included if they were using the PSC instrument in their everyday practice, and if they worked with adult patients in a communitybased practice. The participants were given a training course to learn how to use the draft version of the revised PSC in practice. The evaluation of the field test led to the development of the definitive version of the new PSC.

\section{Results}

The results are reported for each phase of the development process.

\section{Phase 1: identification of the objectives for improvement}

The expert group consisted of nine persons, six experts, and three of the researchers (AS, TvdW, AB). They formulated 12 objectives for the improvement of the PSC instrument (Figure 2, left column). Additionally, the expert group proposed to integrate the new version into an existing and theory-based goal-setting and actionplanning framework (G-AP framework) [25] as also suggested in a previous review [22], and incorporating the model of shared decision making [42]. The G-AP framework describes a cyclic goal-setting process that starts at the first consultation and continuous throughout the course of the treatment [25]. It offers professionals the opportunity to involve patients in the entire process in four phases: goal negotiation, goal setting, planning, and appraisal and feedback. Shared decision making refers to a systematic approach in which the patient is supported by the professional to make an informed decision about treatment options, based on the patient's personal preferences [43].

\section{Phase 2: development of the draft version}

The 12 objectives for improvement were listed in a questionnaire that was sent to the seven physiotherapists from group A. They wrote down potential solutions to address these objectives and returned the questionnaire to the researcher (AS). She summarized the potential solutions and used them as input for the next group meeting. This meeting was attended by six physiotherapists from group $A$, and three researchers ( $A S, A K, A B$ ). The meeting resulted in several suggestions for designing the draft version of the new PSC. Furthermore, the original 12 objectives for improvement were used to formulate four main objectives for developing the PSC instrument into a method, namely: (1) Clear instructions for the physiotherapists on how to administer the method. (2) Targeted use of the method across the physiotherapy process: the selected problem activities serve as a basis for treatment goals and therapy plan, and will be evaluated throughout and at the end of the physiotherapy process. (3) Client-activating communication skills: the physiotherapists stimulate the patient to bring forward his/her ideas in the entire goal-setting process. (4) A client-centered attitude on the part of the physiotherapist. The four circles in the middle column of Figure 2 illustrate the mutual relationships among the objectives for improvement that are necessary for a client-centered attitude of the physiotherapist.

Additionally, the physiotherapists suggested to develop a practical training course to teach physiotherapists how to use the new method in practice. We therefore developed a training course that was based on the principles of the constructivist learning approach [44] and incorporated training methods such as peer assessment [45] and on-the-job learning [46]. The four main learning objectives of the course were based on the four objectives for improvement of the PSC instrument, and were formulated as follows. The physiotherapist is (1) aware of the content and rationale 


\section{Objectives for improvement of the PSC instrument}

Patients are prepared for therapy (problems, goals)

Phy knows the patient's preferences and expectations

Phy informs patient about the purpose of the PSC steps

The PSC can be tailored to every patient

Phy uses the PSC within the goal-setting process (not for mandatory reasons)

Phy knows the stepwise process of the PSC

Identification / selection of problem activities is integrated in history taking

Phy encourages the patient to recall problem activities

Phy specifies the patient's activity problems

The scoring is clear to patient and phy

Selected problem activities are used to set treatment goals

Patients actively participate in setting goals and planning treatment

\section{Four main objectives for improvement}

\section{Adjustments to the PSG method}

The PSG method is fully integrated in the G-AP framework and physiotherapy process

Two extra steps are added: 'setting goals' and 'planning treatment'

Elements of SDM are integrated in the 'planning treatment' step

The meaning of the score is reversed

A clear PSG administration procedure is developed

Instruction is provided to inform patients explicitly and to stimulate participation

A training course is developed to learn to use the PSG method in practice

Figure 2. Development process: from objectives for improvement of the PSC instrument towards the main adjustments to the PSG method. Phy: Physiotherapist; SDM: Shared decision making.

of the method and is able to apply the method correctly, (2) able to fully integrate the method across the physiotherapy process, (3) able to communicate with patients in a client-centered manner within the process of goal setting, and (4) aware of what is meant by client-centeredness and able to provide client-centered physiotherapy using the new method. A course manual was written to guide this course.

The patient meeting was attended by two researchers (AS, AK) and three patients (two women, one man), aged 48, 52, and 58 years, with a chronic disorder (neck-shoulder complaints, multiple sclerosis, hip arthrosis, and leukemia). They were all active members of a patient organization. The patient meeting resulted in several requirements regarding the way patients could be interviewed by the physiotherapist and invited to participate in the goal-setting process. For instance, they emphasized that the questions to identify activities-related problems should not be too complicated, using difficult terminology, nor too simple with scoring on symbols like smileys. They would prefer to be informed about the questions they might expect the physiotherapist to ask them about activity problems prior to the first consultation, by way of a letter, an email, or on the website. The main points of interest to them were that physiotherapists should deliver clientcentered care, take their patients' abilities into account, be flexible and most importantly, listen carefully to their patients.

\section{Phase 3: evaluation of the feasibility in practice}

The draft version of the new method was piloted by four physiotherapists from group A in a two-loop iterative field test. They all used the method for three patients with a chronic disorder. Feedback was obtained in individual interviews (with AS) and by email. The physiotherapists were all positive about the adjustments made to the original PSC instrument to turn it into a method. Overall, the stepwise process and integration across all steps of the physiotherapy process were reported to be feasible and client-centered. They appreciated the ideas about explicitly informing and actively involving patients in deciding about treatment goals and plans, although they found it difficult to actually do so. Furthermore, they were positive about the instruction manual with the administration procedure which included sample questions. They had, however, omitted the proposed first step of preparing patients to think about their problem activities prior to the consultation, because of potential organizational difficulties. There were no pathways available for arranging this in practice, and they thought it would be too difficult for the patients without assistance. The suggestion of giving the patients the administration forms to take home was considered infeasible. Suggestions for improvement were made about the layout of the instructions and adjusting the language to make it easier to interpret. 
PSG method within

G-AP framework

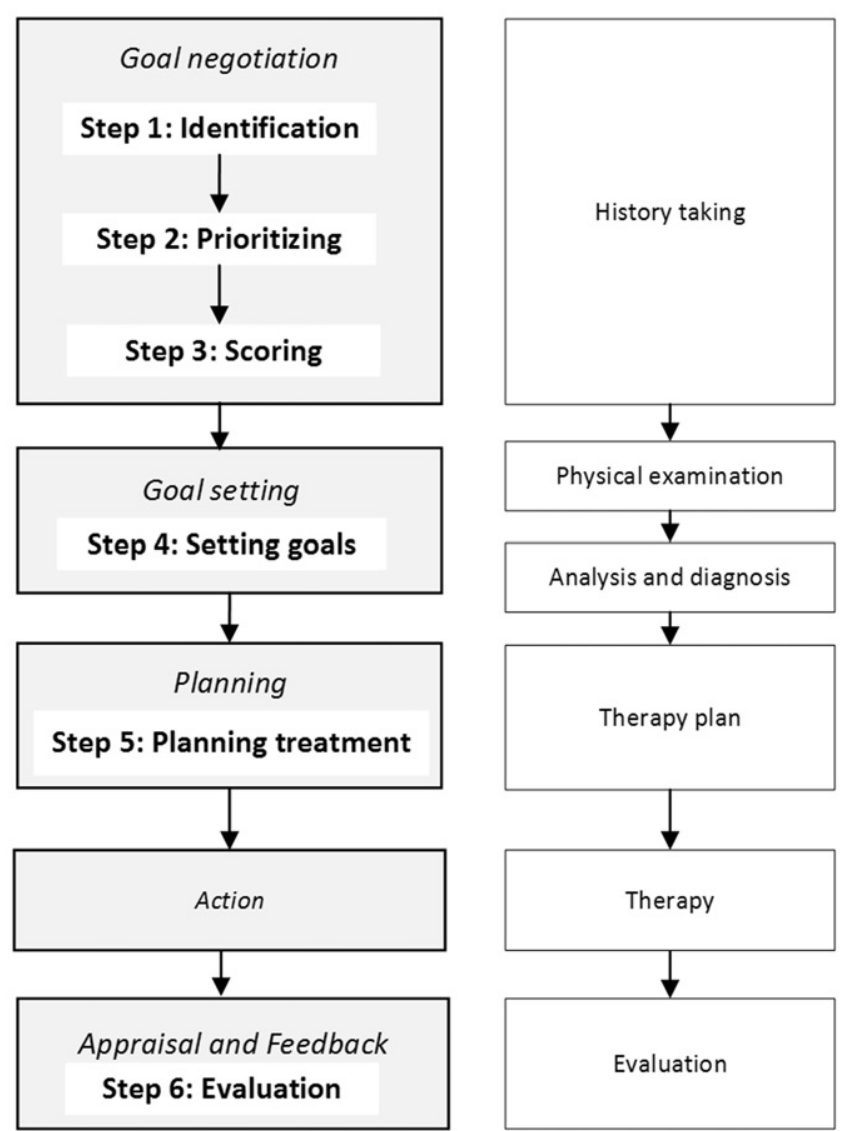

Figure 3. Integration of the PSG method into the G-AP framework and the physiotherapy process.

All feedback was processed into the second draft version, which was subsequently tested and evaluated in the second field test by group $B$, consisting of 12 physiotherapists (three from group A) from six different community practices (five men, seven women), aged 21-57 years (median: 47.5 years). They all attended the practical training course consisting of three 3-h sessions, which was given by two researchers (AS, AK), who were also experienced educators and physiotherapists. Four patients participated in the role plays during the first session (three patients from phase 2, and one additional patient: a woman aged 51 years, with fibromyalgia). They gave feedback to the physiotherapists about their performance, and to the researchers about the patient contribution during the training course. Evaluation of the second field test did not lead to additional changes to the draft version, so this meant that the definitive version of the new PSC, the so-called Patient-Specific Goal-setting method (PSG), was ready. The main adjustments to the PSG method compared to the original PSC instrument are outlined in Figure 2 (right column).

\section{The Patient-Specific Goal-setting method}

The PSG is a method to support physiotherapy goal setting. The method consists of six steps that are integrated into the G-AP framework [25], and across the physiotherapy process (Figure 3).

The six steps are as follows. (1) Identifying problematic activities that the patient encounters in daily life as a consequence of their health problem. (2) Prioritizing the most important activity he/she wants to work on in therapy. (3) Scoring the perceived ability to perform the selected activity on an 11-point NRS ( $0=$ impossible to perform, $10=$ easy to perform). (4) Setting goals, i.e., translating the selected activities into treatment goals. (5) Planning treatment, i.e., making a shared decision about the treatment plan. (6) Evaluating the treatment goals. The first three steps, that is, identifying, prioritizing and scoring are integrated into the goal-negotiation phase of the G-AP framework, and can be applied in the history-taking step of the physiotherapy process, in which the patient's problems are identified. The "setting goals" step is integrated into the goal-setting phase, and can be applied in the analysis and diagnosis step of the physiotherapy process, in which the findings of the physical examination are discussed with the patient. The "planning treatment" step is integrated into the planning phase, after the setting of treatment goals. Elements of shared decision making [42] are integrated in this step, which can be applied in the therapy plan step of the physiotherapy process. The evaluation is integrated into the appraisal and feedback phase, and can be applied in the evaluation step, during or at the end of the treatment program. Essential elements of the PSG method include informing the patient by introducing each step and explaining its rationale, to increase their awareness and readiness for participation. The physiotherapist should use client-activating communication skills to stimulate the patient to express their own ideas about treatment goals and planning.

Each step is described in the PSG instruction manual, which provides information about the aim of each step, the stage of the physiotherapy process in which the step can be applied, and how it has to be applied. Additionally, the manual includes some sample questions and describes some potential problems.

\section{Discussion}

The improvement of the PSC instrument has led to a new method, the PSG method, to support physiotherapy goal setting. With the PSG, patients can be actively involved in identifying, prioritizing and rating their performance of the most important activities they are having problems with due to their disorder. Based on the selected problematic activities, individual treatment goals are set jointly by patient and physiotherapist, after which a shared decision is made about the treatment plan, and the treatment goals can be evaluated after treatment. The follow through of treatment goals at each and every treatment session, is of main importance in this goal-setting method.

During the development process, it became clear that the new version of the instrument could not be applied separately, but was to be fully integrated in the physiotherapy process. Therefore the new version should be seen as a method, and we changed the name into the PSG-setting method to avoid confusion with the original PSC instrument. Training the physiotherapists to use the method in practice seems necessary, as the interaction between physiotherapist and patient, including the client-activating communication skills in the context of a client-centered attitude, is crucial for a correct application.

Due to the user-centered approach the experiences, preferences and knowledge of physiotherapists, patients and experts were incorporated in the PSG method. The four main objectives for improvement were all addressed during the development process: (1) clear instructions for the physiotherapist on how to administer the method, (2) targeted use of the method across the physiotherapy process, (3) client-activating communication skills, and (4) a client-centered attitude on the part of the physiotherapist. The integration into the G-AP framework, and the integration of elements of shared decision making into the "treatment planning" 
step, form the client-centered basis of the method. Patients are informed about the aim of each step in order to increase their awareness and readiness for participation. The six steps of the PSG are fully integrated into the entire physiotherapy process. This makes its use more efficient, targeted and offers the opportunity to focus more fully on the patient's goals for physiotherapy. The added steps of "setting goals" and "planning treatment" also facilitate its targeted use, as these goals and plan can be based on the selected activities. The written instruction manual, including sample questions and potential problems, may contribute to a clearly defined administration procedure. The rating scores have been reversed, so patients rate "easiness to perform" instead of "difficulty to perform", to make scoring clearer and easier for patients. A higher score now means better functioning, and this contributes to a more positive health approach by focusing on the patients' abilities, as incorporated in the new definition of health proposed by the World Health Organization [47].

The patients in our study expressed a preference for a preliminary step to prepare them for the questions that will be asked by the physiotherapist at the start of treatment, but this was considered infeasible by the physiotherapists in our study. We decided to omit this step because there are too many differences in the organizational structure of practices and we were not able to accommodate these differences satisfactorily. Although there is only limited evidence that pre-consultation preparations benefit patients [48], this option still deserves attention, and patients do need time to reflect.

The PSG method has been developed particularly for and with patients with chronic disorders, because they may face multiple problems in managing their daily lives. This is why it is necessary to reflect on the patient's situation, i.e., the activity problems they experience in daily life, as well as to prioritize these activities. Nevertheless, the method might also be useful for other patients in other healthcare settings and for other disciplines, such as occupational therapy and speech and language therapy.

\section{Reflection on methods}

Our development strategy was based on a user-centered design [40]. The experiences of the users of the original version of the PSC instrument, which we had analyzed in a previous study, provided the starting point for our development process $[11,16]$. User participation during the whole development process, as well as the iterative approach including several field tests, resulted in a product, i.e., a method, that was co-developed with physiotherapists and patients. We regarded this user-centered approach as the most appropriate design method for this subject. This approach is often used in the development of technological tools and products [49] but is also applicable in the development of other types of instruments. User involvement in the development and testing process is associated with significant benefits, such as gaining insight into the user's perspective, generating new ideas and improving feasibility [38].

Only four patients participated in our development process. Due to our purposive sampling these patients are not representative for all physiotherapy patients. We selected patients who were able to think at a more abstract level, in discussions with the researchers. The participating physiotherapists were mainly recruited from existing networks and may represent the early innovators in the field. We think, however, that these patients and the early innovators strengthen the creative process and make valuable contributions to the development process. The downside is that we might have suffered from somewhat optimistic bias regarding the feasibility in daily practice.

\section{Comparison with other studies}

We can compare the PSG method with another frequently used patient-specific instrument in occupational therapy: the COPM [29]. The COPM has also been proposed for use in the process of goal setting [22]. It is based on the Canadian Model of Occupational Performance and Engagement (CMOP-E) [50]. Occupational therapists also have to be trained to use the COPM in practice. The client-centered approach of the COPM has proved its value in previous studies [24,51-53]. It differs however, from the PSG method because it is not integrated into a client-centered framework of goal setting and does not include shared decision making. The COPM lacks the extra steps of "setting goals" and "planning treatment", which we included in order to deliver goaloriented care and improve patient participation [26,54].

The PSG method rates the possibility to perform the selected activities. Related to goal setting other measures are proposed, such as, belief in self-confidence and self-efficacy $[25,55]$. These measures can be meaningful to increase patient adherence and might lead to better treatment outcomes. However, the physiotherapists in the first field test indicated that putting in too many ratings would not be feasible in practice. Therefore, we decided not to adopt these extra ratings as a standard option, but they are optional.

\section{Future research and implications for practice}

The next step before large-scale implementation in physiotherapy practices involves testing the feasibility and psychometric properties of the PSG method. This should be done in a larger group of physiotherapists, that is representative of all physiotherapy practices. Furthermore, the effects of the method on different outcomes will have to be investigated.

Even before all this has been realized, physiotherapists can already integrate the ideas underlying the PSG method into daily practice. For example, they can inform their patients about the steps they take to select activity problems, set goals based on the selected activities, and discuss treatment goals and treatment plan explicitly with their patients. This would already improve goal-oriented and client-centered physiotherapy.

\section{Acknowledgements}

We would like to thank the patients and physiotherapists for their participation in this study, and especially Marjo Maas and Vincent Kortleve for their contribution to the development of the training course.

\section{Disclosure statement}

This study was funded by Stichting Innovatieve Alliantie, the Netherlands: grant number RAAK Pro-1-007. The authors report no conflicts of interests.

\section{Funding}

This study was funded by Stichting Innovatieve Alliantie, the Netherlands: grant number RAAK Pro-1-007. 


\section{References}

[1] Reuben DB, Tinetti ME. Goal-oriented patient care-an alternative health outcomes paradigm. $\mathrm{N}$ Engl J Med. 2012;366:777-779.

[2] Mead N, Bower P. Patient-centredness: a conceptual framework and review of the empirical literature. Soc Sci Med. 2000;51:1087-1110.

[3] Lenzen SA, Daniels R, van Bokhoven MA, et al. Setting goals in chronic care: shared decision making as self-management support by the family physician. Eur J Gen Pract. 2015;21:138-144.

[4] Arnetz JE, Almin I, Bergström K, et al. Active patient involvement in the establishment of physical therapy goals: effects on treatment outcome and quality of care. Adv Physiother. 2004;6:50-69.

[5] Hazard RG, Spratt KF, McDonough CM, et al. The impact of personal functional goal achievement on patient satisfaction with progress one year following completion of a functional restoration program for chronic disabling spinal disorders. Spine. 2009;34:2797-2802.

[6] Holliday RC, Ballinger C, Playford ED. Goal setting in neurological rehabilitation: patients' perspectives. Disabil Rehabil. 2007;29:389-394.

[7] Leach E, Cornwell P, Fleming J, et al. Patient centered goalsetting in a subacute rehabilitation setting. Disabil Rehabil. 2010;32:159-172.

[8] Levack WM, Dean SG, Siegert RJ, et al. Purposes and mechanisms of goal planning in rehabilitation: the need for a critical distinction. Disabil Rehabil. 2006;28:741-749.

[9] Baker SM, Marshak HH, Rice GT, et al. Patient participation in physical therapy goal setting. Phys Ther. 2001;81:1118-1126.

[10] Young CA, Manmathan GP, Ward JC. Perceptions of goal setting in a neurological rehabilitation unit: a qualitative study of patients, carers and staff. Acta Derm Venereol. 2008;40:190-194.

[11] Stevens A, Moser A, Koke A, et al. The patient's perspective of the feasibility of a patient-specific instrument in physiotherapy goal setting: a qualitative study. Patient Prefer Adherence. 2016;10:425-434.

[12] Northen JG, Rust DM, Nelson $C E$, et al. Involvement of adult rehabilitation patients in setting occupational therapy goals. Am J Occup Ther. 1995;49:214-220.

[13] Rosewilliam S, Roskell CA, Pandyan AD. A systematic review and synthesis of the quantitative and qualitative evidence behind patient-centred goal setting in stroke rehabilitation. Clin Rehabil. 2011;25:501-514.

[14] Schoeb V. "The goal is to be more flexible" - detailed analysis of goal setting in physiotherapy using a conversation analytic approach. Manual Ther. 2009;14:665-670.

[15] Schoeb V, Burge E. Perceptions of patients and physiotherapists on patient participation: a narrative synthesis of qualitative studies. Physiother Res Int. 2011;17:80-91.

[16] Stevens A, Moser A, Koke A, et al. The use and perceived usefulness of a patient-specific instrument in physiotherapy goal setting. A qualitative study. Muskuloskelet Sci Pract. 2017;27:23-31.

[17] Levack WM, Dean SG, Siegert RJ, et al. Navigating patientcentered goal setting in inpatient stroke rehabilitation: how clinicians control the process to meet perceived professional responsibilities. Patient Educ Couns. 2011;85: 206-213.
[18] Barnard RA, Cruice MN, Playford ED. Strategies used in the pursuit of achievability during goal setting in rehabilitation. Qual Health Res. 2010;20:239-250.

[19] KNGF richtlijn: Fysiotherapeutische Verslaglegging; 2011.

[20] Koninklijk Nederlands Genootschap voor Fysiotherapie, Beroepsprofiel Fysiotherapeut. [Royal Dutch Society for Physical Therapy, Professional Profile for Physical Therapists]; 2014.

[21] WCPT Guidelines for Standards of Physical Therapy Practice; 2011.

[22] Stevens A, Beurskens A, Koke A, et al. The use of patientspecific measurement instruments in the process of goalsetting: a systematic review of available instruments and their feasibility. Clin Rehabil. 2013;27:1005-1019.

[23] Holliday RC, Cano S, Freeman JA, et al. Should patients participate in clinical decision making? An optimised balance block design controlled study of goal setting in a rehabilitation unit. J Neurol Neurosurg Psychiatry. 2007;78:576-580.

[24] Wressle E, Eeg-Olofsson AM, Marcusson J, et al. Improved client participation in the rehabilitation process using a client-centred goal formulation structure. J Rehabil Med. 2002;34:5-11.

[25] Scobbie L, Dixon D, Wyke S. Goal setting and action planning in the rehabilitation setting: development of a theoretically informed practice framework. Clin Rehabil. 2011;25: 468-482.

[26] Scobbie L, McLean D, Dixon D, et al. Implementing a framework for goal setting in community based stroke rehabilitation: a process evaluation. BMC Health Serv Res. 2013;13:190.

[27] Rothman ML, Beltran P, Cappelleri JC, et al. Patientreported outcomes: conceptual issues. Value Health. 2007;10(Suppl 2):S66-S75.

[28] Snyder CF, Aaronson NK, Choucair AK, et al. Implementing patient-reported outcomes assessment in clinical practice: a review of the options and considerations. Qual Life Res. 2012;21:1305-1314.

[29] Law M, Baptiste S, McColl M, et al. The Canadian occupational performance measure: an outcome measure for occupational therapy. Can J Occup Ther. 1990;57:82-87.

[30] Beurskens AJ, de Vet HC, Koke AJ, et al. A patient-specific approach for measuring functional status in low back pain. J Manipulat Physiol Ther. 1999;22:144-148.

[31] Stratford P, Gill C, Westaway $M$, et al. Assessing disability and change on individual patients: a report of a patient specific measure. Physiother Canada. 1995;47:258-263.

[32] Swinkels RA, van Peppen RP, Wittink $H$, et al. Current use and barriers and facilitators for implementation of standardised measures in physical therapy in the Netherlands. BMC Musculoskelet Disord. 2011;12:106.

[33] World Health Organization. International classification of functioning, disabilities and health problems. Geneva: World Health Organization; 2001.

[34] Berghmans DD, Lenssen AF, van Rhijn LW, et al. The patient-specific functional scale: its reliability and responsiveness in patients undergoing a total knee arthroplasty. J Orthop Sports Phys Ther. 2015;45:550-556.

[35] Nijkrake MJ, Keus SH, Quist-Anholts GW, et al. Evaluation of a Patient-Specific Index as an outcome measure for physiotherapy in Parkinson's disease. Eur J Phys Rehabil Med. 2009;45:507-512.

[36] Hefford C, Abbott JH, Arnold R, et al. The patient-specific functional scale: validity, reliability, and responsiveness in patients with upper extremity musculoskeletal problems. J Orthop Sports Phys Ther. 2012;42:56-65. 
[37] Hefford C, Abbott JH, Arnold R, et al. The Patient-Specific Functional Scale (PSFS): responsiveness, reliability and construct validity for patients with upper extremity musculoskeletal problems. N Z J Physiother. 2010;38:67-70.

[38] Shah SG, Robinson I. Benefits of and barriers to involving users in medical device technology development and evaluation. Int J Technol Assess Health Care. 2007;23:131-7.

[39] Stevens JGA, Beurskens AJMH. Implementation of measurement instruments in physical therapist practice: development of a tailored strategy. Phys Ther. 2010;90:953-961.

[40] Gulliksen J, Göransson B, Boivie I, et al. Key principles for user-centred systems design. Behav Inform Technol. 2003;22:397-409.

[41] Delbecq A, Ven van de AH, Gustafson DH. Group techniques for program planning: a guide to nominal and Delphi processes. Glenview III: Scott, Foresman and Company; 1975.

[42] Elwyn G, Frosch D, Thomson R, et al. Shared decision making: a model for clinical practice. J Gen Intern Med. 2012;27:1361-1367.

[43] Makoul G, Clayman ML. An integrative model of shared decision making in medical encounters. Patient Educ Couns. 2006;60:301-312.

[44] Bandura A. Social learning theory. New York: General Learning Press; 1977.

[45] van Dulmen SA, Maas M, Staal JB, et al. Effectiveness of peer assessment for implementing a Dutch physical therapy low back pain guideline: cluster randomized controlled trial. Phys Ther. 2014;94:1396-1409.

[46] Billet S. Learning through work: workplace participatory practices. In: Rainbird H, Fuller A, Munro A, editors. Workplace learning in context. London: Routledge; 2004.

[47] Huber M, Knottnerus JA, Green L, et al. How should we define health? BMJ. 2011;343:d4163.
[48] Kinnersley P, Edwards A, Hood K, et al. Interventions before consultations for helping patients address their information needs. Cochrane Database Syst Rev. 2007;CD004565.

[49] Vermeulen J, Neyens JC, Spreeuwenberg MD, et al. Usercentered development and testing of a monitoring system that provides feedback regarding physical functioning to elderly people. Patient Prefer Adher. 2013;7:843-854.

[50] Polatajko HJ, Townsend EA, Craik J. Canadian Model of Occupational Performance and Engagement (CMOP-E). In: Townsend EA, Polatajko HJ, editors. Enabling occupation II: advancing an occupational therapy vision of health, wellbeing, \& justice through occupation. Ottawa (ON): CAOT Publications ACE; 2007. p. 22-36.

[51] Enemark Larssen A, Carlsson G. Utility of the Canadian Occupational Performance Measure as an admission and outcome measure in interdisciplinary community-based geriatric rehabilitation. Scand J Occup Ther. 2012;19:204-213.

[52] Wressle E, Lindstrand J, Neher $M$, et al. The Canadian Occupational Performance Measure as an outcome measure and team tool in a day treatment programme. Disabil Rehabil. 2003;25:497-506.

[53] Chen $\mathrm{YH}$, Rodger S, Polatajko $H$. Experiences with the COPM and client-centred practice in adult neurorehabilitation in Taiwan. Occup Ther Int. 2002;9:167-184.

[54] Marshall SSHK, Fitzpatrick R. Patient involvement and collaboration in shared decision-making: a structured review to inform chronic disease management. Report from the Patient-reported Health Instruments Group to the Department of Health; 2005.

[55] Ziviani J, Poulsen AA, Kotaniemi K, et al. The Belief in Goal Self-Competence Scale (BiGSS) - exploring a new way to support individual goal pursuit and document occupational therapy outcomes in paediatric practice. Aust Occup Ther J. 2014;61:316-324. 